\title{
Distributive justice in disaster triage
}

\section{Utilitarianism competes with egalitarianism, autonomy, and the physician-patient relation- ship}

Matthew Greenacre, Katherine Fleshner

Faculty Reviewer: Dr. Barry Hoffmaster, PhD (Department of Philosophy)

\section{ABSTRACT}

Disasters that produce an overwhelming number of casualties demand that healthcare resources be rationed. Given the gravity of these decisions, it is imperative that they be guided by acceptable principles of distributive justice. Utilitarianism governs current disaster triage protocols because the efficient use of resources prevents the greatest amount of disability and mortality in the population. However, this conflicts with maximin egalitarianism, which demands that the most severely injured patients be prioritized even if it is not an efficient use of resources. Utilitarian triage also conflicts with the egalitarian principle of equal chances, which states that all people should be given an opportunity to be given treatment since all persons value their lives equally. Utilitarianism protects the needs of the entire population, and so demands that an individual patient's right to autonomy and a fiduciary relationship with their physician must be sacrificed. Like other policies in a democratic society, the legitimacy of disaster triage protocols comes from support by the majority. For this reason, choosing the values that guide disaster triage requires open and transparent communal disaster planning that reflects the values of all members of society. Rather than prioritizing one principle over another, it is likely that the most just approach to allocating resources in disaster triage may be to apply a mixture of distributive justice principles.

\section{INTRODUCTION}

Some natural disasters and conflicts cause an overwhelming surge of severely injured casualties. These circumstance require more lifesaving care than the available medical services can provide, creating a bottleneck in which some patients cannot be saved ${ }^{1-5}$ The fact that some patients will die because there are not enough resources to save all severely injured people is what differentiates disaster triage from normal emergency department triage..$^{1-3,6,7}$ These conditions make triage a decision of which patients will receive curative treatment and which will be categorized as expectant, expected to succumb to their injuries, and be given only palliative care..$^{1,2,5}$

How can one make such a tragic choice justly? The most commonly used and accepted disaster triage algorithms, START and SALT, direct care towards patients that need it to survive, but also prioritizes patients that have the best prognosis., ${ }^{1,8}$ Under these guidelines, patients less likely to survive or needing disproportionate resources are categorized as expectant. ${ }^{1,8,9}$ This article will ex- plain why this utilitarian approach to disaster triage is justified, as well as how utilitarianism conflicts with egalitarian principles of distributive justice, and patient autonomy and the patient-physician fiduciary relationship. Here it is argued that community participation in disaster planning and compromise between values is necessary to resolve these ethical dilemmas.

\section{UTILITARIANISM PROVIDES A JUSTIFICATION FOR WITHHOLDING LIFESAVING CARE}

Utilitarianism can be summarized as valuing "the greatest good for the greatest number" ${ }^{1,10,11}$ Utilitarian triage places a moral imperative on squeezing every drop of life out of the available care. ${ }^{1,12}$ Thus, utilitarian algorithms prioritize patients who need life-saving treatment to survive but are likely to survive with relatively fewer resources. The expectant category includes patients that require relatively more resource-intensive treatments to survive or for whom treatment is futile., ${ }^{1,2}$ The criterion for which patients are too far gone or costly to treat should be set so that the greatest number of lives possible are saved. ${ }^{1,11}$ If one believes that the highest value is to preserve human life whenever possible, then it follows that one ought to maximize the number of lives saved in a disaster. ${ }^{12}$

A second utilitarian approach prioritizes not just the quantity of life, but it's quality. From this perspective, it is favourable to dedicate resources towards patients with a better likelihood of recovery and rehabilitation, as measured by quality-adjusted life years (QALYs). QALYs are an estimate of life expectancy that considers the quality of life of a person's remaining years. ${ }^{12,13}$ Consider two patients of similar age that arrive in the emergency department following an earthquake: one with a traumatic brain injury (TBI) and one with an open bone fracture. Both require surgery, but it is only possible to operate on one of them. Which one? Repairing a fracture is more likely to lead to full rehabilitation. While surgery may save the TBI patient's life, he or she is likely to have a poorer quality of life. In this case, the triage order is assigned to maximize QALYs and the fracture patient is selected. Treating patients with favourable prognoses reduces both morbidity and mortality, which, in turn, achieves more QALYs. ${ }^{13}$

Choosing to maximize the number of long, happy, disease-free lives has an intuitive appeal because it maximizes the total amount of happiness and productivity while minimizing the amount of suffering in the population. ${ }^{12}$ For some ethicists, QALY maximization is also justified by the idea that one must be sufficiently healthy and free of suffering to value life. If one accepts that they should try to save as much positive human experience as possible, then one should attempt to maximize QALYs in their triage algorithm. ${ }^{13}$ Note 
that this does not mean that the greatest number of lives ought to be saved. If treating a young person means withholding treatment from several elderly patients with poor prognoses, one ought to save only the young person's life because they are more likely to live more enriched, disease-free years than the older patients combined. ${ }^{14}$

\section{UTILITARIAN TRIAGE CONFLICTS WITH EGALITARIANISM}

Originally, disaster triage was egalitarian, rather than utilitarian. The earliest records of disaster triage are by Napoleon's army during the 18th century, which was based entirely on the severity of injury. ${ }^{6,15}$ The more severe the injury, the sooner the patient was seen. ${ }^{6}$ This approach is congruent with maximin egalitarianism, which states that if resources must be allocated unequally, they should be distributed such that the worst off benefit the most.,10,12 In maximin disaster triage, the first patients to be seen would be the most severely injured. . $^{1,10-12}$

\section{THUS, UTILITARIAN ALGORITHMS} PRIORITIZE PATIENTS WHO NEED

\section{LIFE-SAVING TREATMENT TO SURVIVE BUT ARE LIKELY TO SURVIVE WITH RELATIVELY FEWER RESOURCES.}

However, utilitarian disaster triage places exactly those patients at the back of the line. ${ }^{9}$ This protocol conflicts with the egalitarian principle of equal chances since it precludes a particular category of patients from receiving treatment at the outset. ${ }^{11}$ This principle states that every person should have an equal chance to receive life-saving treatment. ${ }^{11,12}$ This is based on the idea that every person values their own life as much as any other person values their own life. By using a triage protocol that gives patients an equal chance to receive treatment, such as a lottery or first-come-firstserved, one gives every life the same value and avoids externally ranking the value of human lives. Once a patient is selected for treatment, regardless of how resource intensive or poor the prognosis, they receive it until they are healed, expire, or decide otherwise. Equality of opportunity to receive treatment, rather than outcome, is paramount. ${ }^{11}$

\section{UTILITARIAN TRIAGE IGNORES PATIENT AUTONOMY AND THE FIDUCIARY RELATIONSHIP}

Utilitarian disaster triage prioritizes maximizing population health over the health of any particular individual., ${ }^{2,3,9,11}$ In doing so, it directly conflicts with two of the fundamental ethical principles of medical practice: patient autonomy and the patient-physician fiduciary relationship. In normal practice, the physician advocates for a single patient's right to treatment, regardless of its cost to the public. In utilitarian triage, healthcare providers cannot fulfill the fiduciary duty as they may have to withhold treatment from one patient to help several others, or a patient with a better prognosis. ${ }^{4,11}$ If healthcare providers choose to use a first-come-first-served system of triage, they may uphold their fiduciary relationships by choosing to only accept a new patient once one of their current patients completes their treatment. ${ }^{16}$

Strict adherence to a disaster triage algorithm removes decisions about which patients should receive how much care from the hands of both physicians and patients., ${ }^{3,11}$ When awake and capable, patients may give consent or refuse treatment but they cannot demand it, even if it is life-saving. ${ }^{3,9}$ Thus, the scope of patient and physician autonomy is constrained. ${ }^{3,49}$ Even the triage officer must comply with the prescriptions of the pre-established triage protocol. ${ }^{11}$ In utilitarian disaster triage, individual rights such as autonomy and the fiduciary relationship are often superseded by the needs of the population to minimize the loss of life and limb., ${ }^{9,11}$

\section{COMPROMISE AND COMMUNAL DISASTER PLANNING}

In the current plans for a disaster, utilitarian triage is most often mandated. Indeed, international humanitarian law currently demands that triage protocols provide the best opportunity to survive. However, the majority of disaster triage protocols have been developed by public health institutions and it is not clear that they would be acceptable to modern Western societies. ${ }^{1}$ In Western democracies, disaster triage policies are ideally legitimate because a sufficient majority of the population or representatives of the effected population have agreed with it., ${ }^{1,311,12}$ Thus, transparent, communal disaster planning that involves representatives of all groups within society is necessary to decide which ethical principles should govern disaster triage. ${ }^{1,3,11,12,17}$

When making tragic choices, such as in disaster triage, one may minimize the offensiveness that comes from choosing one strongly held over another by compromising. This means allowing triage to be performed using a mixture of methods that represent each competing value. ${ }^{12,18}$ For example, one could use a mix of first-comefirst-served and utilitarian triage. Also, once patients are triaged and have begun to receive treatment, choosing not to withdraw it based on utilitarian re-allocation of resources maintains the fiduciary relationship and as much patient autonomy as possible. ${ }^{16}$

\section{CONCLUSION}

Utilitarianism directs most disaster triage protocols towards saving as many lives and preventing as much disability as possible. However, by adopting this population-level goal, one must ignore the bioethics that usually govern medical practice and protect individual patients. Utilitarian triage also conflicts with egalitarian theories of distributive justice, for which there are good arguments. Despite its ubiquity, it is not known whether the populations that would be subjected to utilitarian triage protocols in a disaster actually find them acceptable. For these protocols to be legitimate policy, they should be approved by a consensus of individuals that adequately represent the interests of all members of society. Should such a group require it, one may reconcile the conflict between the competing principles by creating a variety of protocols and methods guided the competing theories. 


\section{REFERENCES}

1. Sztajnkrycer MD, Madsen BE, Alejandro Báez A. Unstable Ethical Plateaus and Disaster Triage. Emerg Med Clin North Am. 2006;24(3):749-68.

2. Geale SK. The ethics of disaster management. Disaster Prev Manag. 2012;21(4):445-62.

3. Petrini C. Triage in public health emergencies: Ethical issues. Intern Emerg Med. 2010;5(2):137-44.

4. O'Laughlin DT, Hick JL. Ethical issues in resource triage. Respir Care. 2008;53(2):190-197-200.

5. Matzo M, Wilkinson A, Lynn J, Gatto M, Phillips S. Palliative care considerations in mass casualty events with scarce resources. Biosecurity and Bioterrorism. 2009;7(2):199-210.

6. Iserson K V., Moskop JC. Triage in Medicine, Part I: Concept, History, and Types. Ann Emerg Med. 2007;49(3):275-81.

7. Kuschner WG, Pollard JB, Ezeji-Okoye SC. Ethical triage and scarce resource allocation during public health emergencies: tenets and procedures. Hosp Top. 2007;85(3):16-25.

8. Lee $\mathrm{CH}$. Disaster and mass casualty triage. Virtual Mentor. 2010;12(6):466-70.

9. Karadag CO, Hakan AK. Ethical Dilemmas in Disaster Medicine. Iran Red Crescent Med J. 2012;14(10):602-12.

10. Olsen JA. Theories of justice and their implications for priority setting in health care. Journal of health economics. 1997;16(6):625-39. PubMed PMID: 10176776.

11. Moskop JC, Iserson K V. Triage in Medicine, Part II: Underlying Values and Principles. Ann Emerg Med. 2007;49(3):282-7.

12. Persad G, Wertheimer A, Emanuel EJ. Principles for allocation of scarce medical interventions. Lancet. Elsevier Ltd; 2009;373(9661):423-31.

13. Cubbon J. The principle of QALY maximisation as the basis for allocating health care resources. Journal of medical ethics. 1991;17(4):181-4. PubMed PMID: 1787516; PubMed Central PMCID: PMC1376052.

14. Harris J. Unprincipled QALYs: a response to Cubbon. JMedEthics. 1991;17(2):185-8.

15. Fink S. Playing God. Radiolab. 2016 Aug 21 [cited 2016 Dec 4]. Available from: http://www.radiolab.org/story/playing-god/.

16. Eyal N, Firth P. Repeat triage in disaster relief: Questions from Haiti. PLoS Curr. 2012;(OCTOBER 2012):1-8.

17. Holt GR. Making difficult ethical decisions in patient care during natural disasters and other mass casualty events. Otolaryngol - Head Neck Surg. 2008;139(2):181-6

18. Hoffmaster B, Hooker C. Tragic choices and moral compromise: The ethics of allocating kidneys for transplantation. Milbank Q. 2013;91(3):528-57.

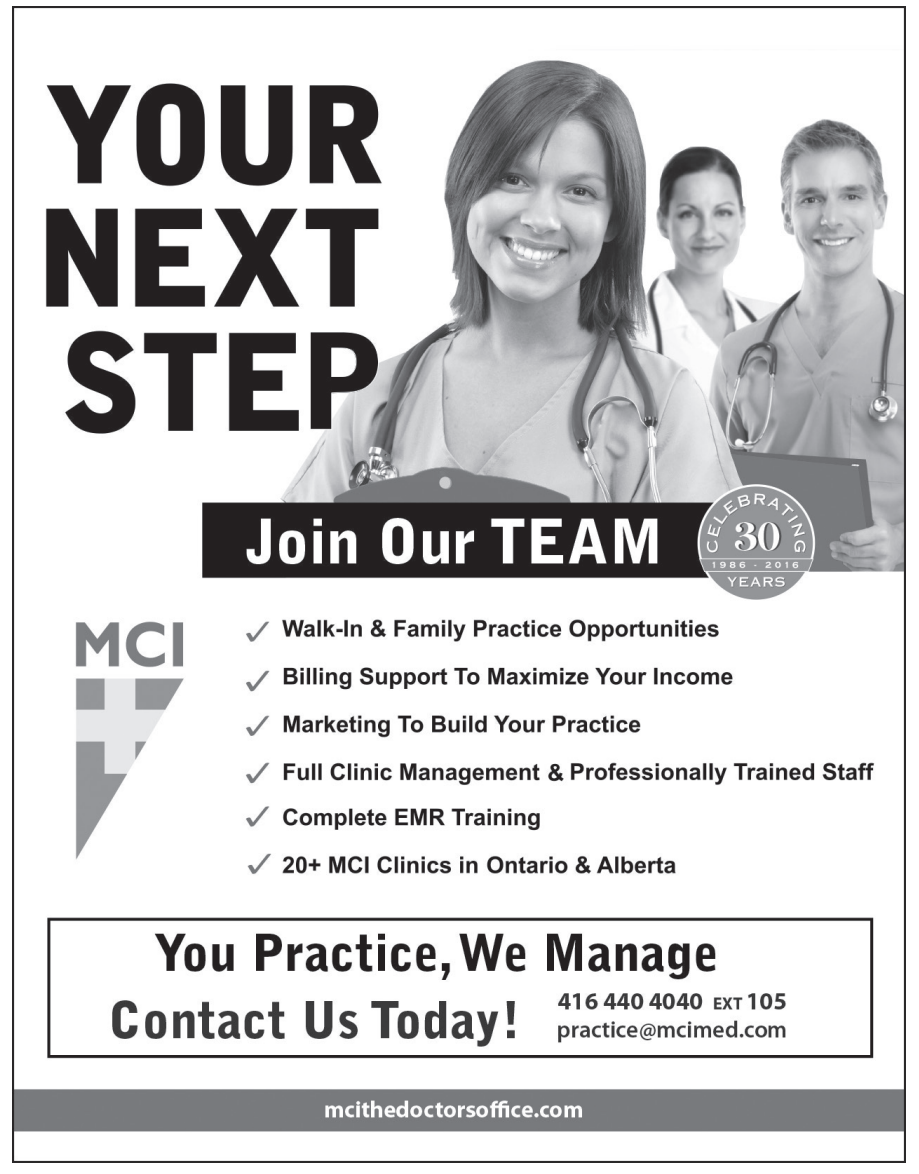

